\title{
BMJ
}

\section{Survival times in people with dementia: analysis from population based cohort study with 14 year follow-up}

\author{
Jing Xie, research associate, ${ }^{1}$ Carol Brayne, professor, ${ }^{1}$ Fiona E Matthews, senior research scientist, ${ }^{2}$ \\ and the Medical Research Council Cognitive Function and Ageing Study collaborators
}

${ }^{1}$ Department of Public Health and Primary Care, Institute of Public Health, University of Cambridge, Cambridge CB2 OSR

${ }^{2}$ MRC Biostatistics Unit, Institute of Public Health, Cambridge

Correspondence to: C Brayne carol.brayne@medschl.cam.ac.uk

doi:10.1136/bmj.39433.616678.25

\section{ABSTRACT}

Objectives To provide estimates of survival after onset of dementia by age, sex, self reported health, disability, and severity of cognitive impairment.

Design Analysis of participants from prospective population based cohort study in 1991-2003, with followup of dementia status in all individuals after two and six years (in one centre) and 10 years and in subsamples additionally at six and eight years and mortality until 2005.

Setting Multicentre population based study in England and Wales: two rural and three urban centres.

Participants 438 participants who developed dementia from a population based study of 13004 individuals aged 65 years and over drawn from primary care population registers.

Main outcome measures Sociodemographic factors, cognitive function, specific health conditions, and self reported health collected at each interview. Cox's proportional hazards regression models were used to identify predictors of mortality from the selected variables in people who received diagnosis of dementia according the study's criteria.

Results By December 2005, 356 of the 438 (81\%) participants who developed dementia during the study had died. Estimated median survival time from onset of dementia to death was 4.1 years (interquartile range 2.57.6) for men and 4.6 years (2.9-7.0) for women. There was a difference of nearly seven years in survival between the younger old and the oldest people with dementia: 10.7 (25th centile 5.6) for ages 65-69; 5.4 (interquartile range 3.4-8.3) for ages 70-79; 4.3 (2.8-7.0) for ages 80-89, and $3.8(2.3-5.2)$ years for ages $\geq 90$. Significant factors that predicted mortality in the presence of dementia during the follow-up included sex, age of onset, and disability. Conclusion These analyses give a population based estimated median survival for incident dementia of 4 . 5 years. Such estimates can be used for prognosis and planning for patients, carers, service providers, and policy makers.

\section{INTRODUCTION}

Life expectancy is increasing globally. One consequence is that the number of people affected by dementia is estimated to double every 20 years to
81.1 million by $2040 .{ }^{1}$ A Delphi consensus study of global prevalence of dementia estimated that 24.3 million people have dementia, with 4.6 million new cases every year. ${ }^{1}$ Dementia is also a major cost to health care and social systems in the developed world. In the United Kingdom in 1998, the institutional cost of people with cognitive impairment $(n=224000)$ was estimated at $0.6 \%$ of the UK gross domestic product (£4.1bn, $€ 5.7 \mathrm{bn}, \$ 8.2 \mathrm{bn}) .{ }^{2}$ Given its impact on society, improvements in our understanding of causes, course, and consequences of dementia are of key importance.

One frequently raised question in clinical and policy settings is the impact of dementia on life expectancy. People with dementia have markedly decreased survival rates compared with those without dementia $^{3-5}$ and are two to four times more likely to die at a given age than those of the same age without dementia. ${ }^{67}$ Even mild cognitive impairment is associated with the increased relative risk of mortality. ${ }^{68}$ The median survival time of patients with dementia has been investigated in cohort studies and case series in various settings and ranges from three to nine years. ${ }^{479}$ Characteristics reported to be associated with variation in survival include age, sex, sociodemographic characteristics, initial severity of dementia, type of dementia, other comorbid conditions, and genetic characteristics. The high mortality in people with dementia persists into the older age group. ${ }^{3610}$ Sex is less related, ${ }^{11} 12$ although most studies report shorter survival in men across all age groups compared with women. ${ }^{10}$ The influence of education is also inconsistent, with some reports of increased mortality with lower levels of education ${ }^{13}$ while others report no such relation $^{14}$ or even the reverse. ${ }^{15}$ The more severe the dementia, the higher the risk of mortality over the long term, ${ }^{1016}$ but again, this finding is not consistent. ${ }^{17}$

Variation in survival might also be caused by differences in study design. Some studies are population based, ${ }^{18} 19$ others community based, ${ }^{3410}$ and some are institution based. ${ }^{20}$ Shorter survival is reported in institutional compared with community based settings. ${ }^{21}$ Some are control studies, others are case control or case series. ${ }^{34}$ Different diagnostic criteria for dementia and age at diagnosis might result in differential survival time. ${ }^{1322}$ Most studies are based 


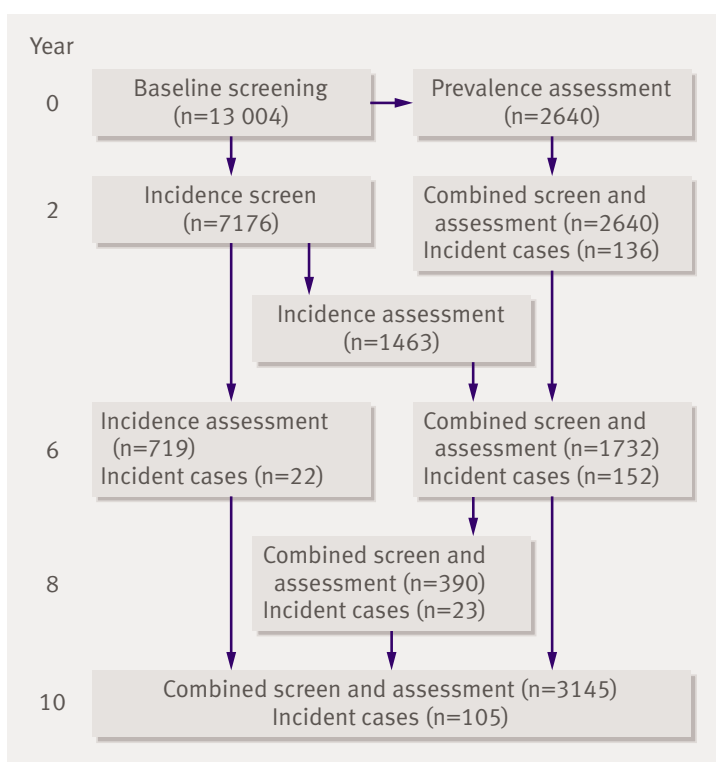

Flowchart of incident dementia cases

on prevalent cases, which could lead to bias because of the exclusion of patients with relatively rapid progressive dementia. ${ }^{1323}$ Analysis that uses incident dementia avoids this bias, but introduces other difficulties such as how to decide the time of onset, which could be based on dates of first symptoms and first consultation, median time between two interviews, or initial clinical diagnosis. Few studies have investigated the difference, but one study reported a median survival of 5.7 years from diagnosis of dementia, but 10.5 years from onset of first reported symptomatic sign. ${ }^{3}$

There is considerable uncertainty about what influencessurvival of people with dementia in the real population. Thisis an important public health issue and provides information for policy makers, practitioners, and families. ${ }^{24}$ We have already shown that dementia and severe cognitive impairment can be present at the end of life, increasingly so with increasing age. ${ }^{25} \mathrm{We}$ looked at overall survival for people with dementia and examined the association between factors that could affect survival in incident dementia over a 14 year follow-up.

\section{METHODS}

\section{Study design and population}

The Medical Research Council's cognitive function and ageing study (MRC CFAS) is a multicentre, longitudinal, prospective population based epidemiological study of cognitive function and disability in the UK. The fieldwork methods were standardised for Cambridgeshire, Gwynedd, Newcastle, Nottingham, and Oxford, where at least 2500 people aged 65 years and over were interviewed at each centre, divided equally between two age groups: $65-74$ and 75 years and over. The sampling included institutions, and the overall response rate $(82 \%)$ provides good population representation. Details of the study design and a description of the baseline sample are reported elsewhere. ${ }^{26}$ Incidence was measured at a two year repeat of these.

Participants were re-interviewed over a 10 year period and followed up for mortality for 14 years. All participants underwent a screening interview for the baseline examination, with $20 \%$ being assessed in a more detailed interview after a median of three months. At two years interviews consisted of an incidence screen for those who had not previously been selected for assessment followed by a selection of $20 \%$ for assessment and combined screen and assessment for those who had been assessed previously at baseline. The assessment sample (representing 20\% of those screened) at both baseline and two year interviews represented all those with cognitive impairment (using AGECAT algorithm and mini-mental state examination scores) and a random sample above mini-mental state examination score cut points. The combined screen and assessment interview was repeated at six, eight, and 10 years. All interviews contained the minimental state examination. The Cambridge centre additionally interviewed the complete sample with a combined screen and assessment interview at six years. At the time of most assessment interviews, and when a diagnosis of dementia was likely from the combined screen and assessment interviews, a participant's relative or carer underwent an informant assessment interview, also known as the history and aetiology schedule. We included in the analysis incident dementia cases in all individuals after two, six (in Cambridge), and 10 years and in subsamples additionally at six and eight years.

Participants were flagged at the Office for National Statistics National Health Service Central Register so we received an automatic notification of death. We collected date of death for all those who died on or before 31 December 2005.

All participants gave informed consent when appropriate and next of kin gave assent on the wishes of the respondent when capacity to make informed decisions was impaired.

\section{Definition of incident dementia}

The assessment comprised standardised questions required for the identification of major psychiatric disorders of old age (the geriatric mental state examination). Diagnosis of incident dementia was based on the geriatric mental state examination algorithm at the assessment interview. ${ }^{27}$ This is a validated algorithm most similar to Diagnostic and Statistical Manual of Mental Disorders (third edition). We classed the time of onset of dementia as the midpoint between the last follow-up without dementia and the first follow-up with dementia.

\section{Cognitive impairment within dementia}

Cognitive function was measured with the mini-mental state examination. ${ }^{28}$ If a non-physical question was not asked or any item was skipped, a person's score was set to missing. Scores for those unable to complete all items because of physical difficulties such as blindness were 
coded as zero. The score was divided into four groups $(\leq 17,18-21,22-25$, and 26-30). Lower scores suggest poorer cognitive function. If a score is missing it means that participants could not be tested and are considerably impaired.

\section{Associated factors}

In keeping with the findings of other studies we included variables known to have an association with mortality: age, sex, marital status, accommodation type, education level, social class, functional status, self reported health, and area deprivation. ${ }^{3461322}$
Functional impairment (disability)_Functional health status was measured using Blessed dementia scale items. Scores ranged from 0-17. The score was calculated for individuals for whom an informant was interviewed - that is, at prevalence assessment, incidence assessment, and at combined screen and assessments at baseline and two, six, eight, and 10 years. We divided the scores into thirds for analysis.

Self reported health-Self reported health was measured with a four point scale, based on the question: "How would you say your health is these days: Would you say your health is excellent, good, fair, or poor?"

Table 1 | Characteristics of 438 incident dementia cases in the Medical Research Council's cognitive function and ageing study. Figures are numbers (percentages) unless stated otherwise

\begin{tabular}{|c|c|c|c|}
\hline Variables* & Women $(n=311)$ & Men $(n=127)$ & Total \\
\hline Median (IQR) age at onset & $84(80-88)$ & $83(77-87)$ & $84(79-88)$ \\
\hline Median (IQR) age at death & $90(85-93)(n=252)$ & $87(83-91)(n=104)$ & $89(84-92)(n=356)$ \\
\hline \multicolumn{4}{|l|}{ Education in years: } \\
\hline$\leq 9$ & $217(71)$ & $91(73)$ & $308(71)$ \\
\hline $10-11$ & $56(18)$ & $25(20)$ & $81(19)$ \\
\hline$\geq 12$ & $34(11)$ & $8(7)$ & $42(10)$ \\
\hline \multicolumn{4}{|l|}{ Social class: } \\
\hline $1 / 11$ & $83(27)$ & $32(25)$ & $115(26)$ \\
\hline III & $129(41)$ & $62(49)$ & $191(44)$ \\
\hline IV/V & $82(26)$ & $31(24)$ & $113(26)$ \\
\hline Armed force/unclassified & $17(6)$ & $2(2)$ & $19(4)$ \\
\hline \multicolumn{4}{|l|}{ Accommodation type: } \\
\hline Community $†$ & $188(61)$ & $90(71)$ & $278(64)$ \\
\hline Residential and nursing home & 122 (39) & 37 (29) & $159(36)$ \\
\hline \multicolumn{4}{|l|}{ Marital status: } \\
\hline Married/cohabiting & $30(10)$ & $12(10)$ & $42(10)$ \\
\hline Single & $61(20)$ & $71(58)$ & $132(31)$ \\
\hline Widowed & $213(70)$ & $39(32)$ & 252 (59) \\
\hline \multicolumn{4}{|l|}{ Townsend deprivation index: } \\
\hline Top third & $108(36)$ & $42(33)$ & $150(36)$ \\
\hline Middle third & $105(35)$ & $40(32)$ & $145(34)$ \\
\hline Bottom third & $84(29)$ & $44(35)$ & $128(30)$ \\
\hline \multicolumn{4}{|l|}{ Self reported health: } \\
\hline Excellent & $44(14)$ & $15(12)$ & $59(13)$ \\
\hline Good & $141(45)$ & $52(41)$ & $193(44)$ \\
\hline Fair & $85(27)$ & $39(31)$ & $124(28)$ \\
\hline Poor & $26(12)$ & $15(12)$ & $41(9)$ \\
\hline Missing & $15(5)$ & $6(5)$ & $21(5)$ \\
\hline \multicolumn{4}{|l|}{ Blessed dementia scale: } \\
\hline Least impaired third & $74(24)$ & $36(28)$ & $110(25)$ \\
\hline Middle impaired third & $73(23)$ & $29(23)$ & $102(23)$ \\
\hline Most impaired third & $82(26)$ & $23(18)$ & $105(24)$ \\
\hline Missing & $82(26)$ & $39(31)$ & $121(28)$ \\
\hline \multicolumn{4}{|l|}{ Mini-mental state examination: } \\
\hline $26-30$ & $3(1)$ & $4(3)$ & $7(2)$ \\
\hline $22-25$ & $27(9)$ & $18(14)$ & $45(10)$ \\
\hline $18-21$ & $63(20)$ & $33(26)$ & $96(22)$ \\
\hline $0-17$ & $167(54)$ & $52(41)$ & $219(50)$ \\
\hline Missing & $51(16)$ & $20(16)$ & 71 (16) \\
\hline
\end{tabular}

$\mathrm{IQR}=$ interquartile range.

*Missing data for $7,1,12$, and 15 in education, accommodation type, marital status, and Townsend deprivation index, respectively. †Community accommodation (own home, granny flat, or warden controlled accommodation). 
Deprivation - The Townsend deprivation score was chosen as a measure of area level deprivation. Based on the 1991 census data, we calculated the score from the respondents' postcodes at baseline screen.

\section{Statistical analyses}

We excluded individuals with prevalent dementia at entry into the cohort from these analyses. All participants alive on or after 31 December 2005 were censored in the analysis. Person years of observation were defined as the interval between the date of onset of dementia and death or 31 December 2005. We excluded individuals seen only at baseline, two years, and 10 years as we could not estimate the onset of dementia between the two follow-ups.

We compared demographic and health characteristics for those with dementia with Mann-Whitney $\mathrm{U}$ test for continuous variables and with Person $\chi^{2}$ test for categorical variables.

Potential predictors included in the models were age at onset of dementia $(65-69,70-79,80-89$, and $\geq 90$ years), sex, educational level $(\leq 9,10-11$, $\geq 12$ years), marital status (married/cohabiting, widowed/separated, and single), social class

\begin{tabular}{|c|c|c|c|}
\hline & Women & Men & All \\
\hline Sex & $4.6(2.9-7.0)$ & $4.1(2.5-7.6)$ & $4.5(2.8-7.0)$ \\
\hline \multicolumn{4}{|l|}{ Median age at onset: } \\
\hline $65-69$ & 7.5 (4.8-NA) & NA (9.1-NA) & 10.7 (5.6-NA) \\
\hline $70-79$ & $5.8(3.6-8.3)$ & $4.6(3.0-8.6)$ & $5.4(3.4-8.3)$ \\
\hline $80-89$ & $4.4(2.8-7.0)$ & $3.7(2.5-6.3)$ & $4.3(2.8-7.0)$ \\
\hline$\geq 90$ & $3.9(2.4-5.2)$ & $3.4(1.5-5.5)$ & $3.8(2.3-5.2)$ \\
\hline \multicolumn{4}{|l|}{ Education (years): } \\
\hline$\leq 9$ & $4.7(3.1-7.3)$ & $4.0(2.8-7.0)$ & $4.6(2.9-7.0)$ \\
\hline $10-11$ & $4.5(3.0-7.1)$ & $3.3(2.2-6.6)$ & $4.0(2.8-6.6)$ \\
\hline$\geq 12$ & $3.6(2.0-6.7)$ & $4.2(1.9-8.6)$ & $3.7(2.0-6.7)$ \\
\hline \multicolumn{4}{|l|}{ Social class: } \\
\hline $1 / 11$ & $4.7(2.7-6.8)$ & $4.2(2.2-7.0)$ & $4.6(2.7-6.9)$ \\
\hline III & $4.6(3.2-7.5)$ & $3.8(2.5-6.6)$ & $4.1(2.9-7.0)$ \\
\hline IV/V & $4.9(2.9-7.3)$ & $5.2(2.6-10.6)$ & $5.0(2.9-8.3)$ \\
\hline Unclassified & $3.3(2.0-5.8)$ & $4.0(4.0-5.5)$ & $3.8(2.0-5.8)$ \\
\hline \multicolumn{4}{|l|}{ Accommodation type: } \\
\hline Community & $4.9(3.2-8.3)$ & $4.6(3.1-7.9)$ & $4.9(3.2-8.2)$ \\
\hline Residential and nursing home & $4.0(2.6-5.9)$ & $2.8(2.0-4.1)$ & $3.7(2.3-5.8)$ \\
\hline \multicolumn{4}{|l|}{ Marital status: } \\
\hline Widowed & $4.4(2.8-6.5)$ & $3.6(2.5-5.2)$ & $4.3(2.8-6.4)$ \\
\hline Married/cohabiting & $7.0(3.5-10.1)$ & $4.2(2.4-7.6)$ & $5.0(3.2-8.6)$ \\
\hline Single & $3.3(2.5-5.9)$ & $4.0(2.8-9.6)$ & $3.8(2.6-7.0)$ \\
\hline \multicolumn{4}{|l|}{ Third of Townsend deprivation scale: } \\
\hline First & $4.7(3.2-7.0)$ & $3.8(2.8-7.0)$ & $4.6(3.0-7.0)$ \\
\hline Second & $4.9(2.9-7.0)$ & $4.1(2.8-6.5)$ & $4.7(2.9-7.0)$ \\
\hline Third & $4.0(2.6-7.5)$ & $4.0(2.2-9.6)$ & $4.0(2.5-7.7)$ \\
\hline \multicolumn{4}{|l|}{ Self reported health: } \\
\hline Excellent & $5.0(3.3-9.1)$ & $4.5(2.8-6.1)$ & $4.9(2.8-8.7)$ \\
\hline Good & $4.7(3.0-7.0)$ & $4.2(2.6-9.1)$ & $4.6(3.0-7.0)$ \\
\hline Fair & $4.5(3.0-6.5)$ & $3.4(2.2-6.8)$ & $4.4(2.8-6.6)$ \\
\hline Poor & $3.2(2.0-5.8)$ & $4.1(2.4-7.6)$ & $3.8(2.3-6.3)$ \\
\hline \multicolumn{4}{|l|}{ Third of Blessed dementia scale: } \\
\hline First & $6.4(4.0-10.0)$ & $6.6(3.9-10.4)$ & $6.4(4.0-10.4)$ \\
\hline Second & $4.0(3.0-6.0)$ & $4.6(2.6-6.3)$ & $4.2(2.8-6.0)$ \\
\hline Third & $3.4(2.4-5.4)$ & $2.9(1.5-5.1)$ & $3.3(2.2-5.3)$ \\
\hline Missing & $4.8(3.2-7.0)$ & $3.6(2.8-5.5)$ & $4.6(2.9-7.0)$ \\
\hline \multicolumn{4}{|l|}{ Mini-mental state examination: } \\
\hline $26-30$ & NA (3.4-NA) & NA (4.6-NA) & NA (4.6-NA) \\
\hline $22-25$ & $7.0(4.6-\mathrm{NA})$ & $4.6(3.1-6.6)$ & $6.1(3.9-10.4)$ \\
\hline $18-21$ & $4.9(3.2-7.5)$ & $4.6(2.9-7.6)$ & $4.7(3.0-7.6)$ \\
\hline $0-17$ & $4.5(2.8-6.8)$ & $3.8(2.2-6.5)$ & $4.3(2.8-6.6)$ \\
\hline Missing & $3.9(1.9-5.4)$ & $3.0(2.0-3.9)$ & $3.6(2.0-5.4)$ \\
\hline
\end{tabular}


(professionals (I), managerial and technical workers (II), skilled non-manual and manual (III), partly skilled workers (IV), and unskilled manual workers (V)), accommodation type (community $v$ institution), third of Townsend deprivation score, Blessed dementia scale (least impaired, middle, and most impaired thirds), score on the mini-mental state examination $(\leq 17,18$ 21, 22-25, 26-30), and self reported health (excellent, good, fair, or poor). The values of potentially time dependent variables were taken from the interview closest to the estimated onset of dementia. For the $40 \%$ with missing data for self reported health, we took that from the closest interview.

Mortality was calculated by dividing the number of individuals who had died by person years at risk during the 14 years of follow-up. We used the Kaplan-Meier method to calculate median survival times from date of onset of dementia and log rank tests to evaluate the survival distributions of different groups. Factors associated with death were analysed with Cox's proportional hazards regression model, which included only those factors that were significant in the univariate analysis. We used Schoenfeld residual tests to evaluate the proportional hazard assumption and checked interactions between variables. This model generates regression coefficients for the independent variables, the exponents of which reflect hazard ratios. All data were analysed with Stata software, version 9.2
(Stata Corp, College Station, TX). The dataset we used was version 8.1 of the Medical Research Council's cognitive function and ageing study.

\section{RESULTS}

\section{Descriptive characteristics}

At baseline, 13004 participants were included in the cohort. A total of 438 incident dementia cases were available from 1991 to 2003 (figure). Of all the participants, $41 \%$ had intervals of two years or less between the interviews that measured the transition from no dementia to dementia. Table 1 shows characteristics of the participants.

The median age at onset of dementia was 84 (interquartile range 80-88) for women and 83 (77-87) for men $(\mathrm{P}=0.001$ for difference). Two thirds of individual cases were women $(311,71 \%)$. Among the 356 who died, the median age at death was 90 for women and 87 for men $(\mathrm{P}=0.001)$. Compared with men, women were more likely to be widowed $(70 \% v$ $32 \%, \mathrm{P}=0.001)$ and living in residential and nursing homes (39\% v29\%, $\mathrm{P}=0.001)$. Women had lower scores on the mini-mental state examination (median $16 v 18$, $\mathrm{P}=0.006)$.

Impact of dementia on median survival time and mortality We derived all median survival times from KaplanMeier estimates from onset of dementia. During the

\begin{tabular}{|c|c|c|c|c|}
\hline & \multicolumn{2}{|c|}{ Univariate analysis } & \multicolumn{2}{|c|}{ Multivariable analysis } \\
\hline & $\mathrm{HR}(95 \% \mathrm{Cl})$ & P value & $\mathrm{HR}(95 \% \mathrm{Cl})$ & $P$ value \\
\hline \multicolumn{5}{|l|}{ Sex: } \\
\hline Women & 1 & \multirow{2}{*}{0.7} & 1 & \multirow{2}{*}{0.007} \\
\hline Men & $1.0(0.8$ to 1.3$)$ & & 1.4 & \\
\hline \multicolumn{5}{|l|}{ Age at onset: } \\
\hline $65-69$ & 1 & \multirow{4}{*}{$<0.001$} & 1 & \multirow{4}{*}{0.03} \\
\hline $70-79$ & 3.3 (1.4 to 7.5$)$ & & 2.1 (0.9 to 4.9$)$ & \\
\hline $80-89$ & 4.5 (2.0 to 10.2$)$ & & 2.7 (1.1 to 6.3$)$ & \\
\hline$\geq 90$ & $6.4(2.7$ to 15.0$)$ & & 3.1 (1.3 to 7.5$)$ & \\
\hline \multicolumn{5}{|l|}{ Accommodation type: } \\
\hline Community & 1 & \multirow{2}{*}{$<0.001$} & 1 & \multirow{2}{*}{0.14} \\
\hline Residential and nursing home & 1.6 (1.3 to 2.0$)$ & & $1.2(0.9$ to 1.6$)$ & \\
\hline \multicolumn{5}{|l|}{ Marital status: } \\
\hline Widowed & 1 & \multirow{3}{*}{0.005} & 1 & \multirow{3}{*}{0.2} \\
\hline Married/cohabiting & 0.7 (0.5 to 0.9$)$ & & 0.7 (0.6 to 1.0$)$ & \\
\hline Single & 0.9 (0.6 to 1.3$)$ & & $0.9(0.6$ to 1.4$)$ & \\
\hline \multicolumn{5}{|l|}{ Third of Blessed dementia scale: } \\
\hline First & 1 & \multirow{4}{*}{$<0.001$} & 1 & \multirow{4}{*}{0.002} \\
\hline Second & 2.1 (1.5 to 2.9$)$ & & $1.8(1.3$ to 2.5$)$ & \\
\hline Third & 2.9 (2.1 to 4.0$)$ & & 2.1 (1.6 to 3.3$)$ & \\
\hline Missing & 1.9 (1.4 to 2.6$)$ & & $1.6(1.2$ to 2.2$)$ & \\
\hline \multicolumn{5}{|l|}{ Mini-mental state examination: } \\
\hline $26-30$ & $0.1(0.03$ to 0.5$)$ & \multirow{5}{*}{$<0.001$} & $0.3(0.1$ to 1.5$)$ & \multirow{5}{*}{0.3} \\
\hline $22-25$ & $0.6(0.4$ to 0.8$)$ & & $0.8(0.5$ to 1.2$)$ & \\
\hline $18-21$ & $0.9(0.7$ to 1.2$)$ & & 1.2 (0.9 to 1.6$)$ & \\
\hline $0-17$ & 1 & & 1 & \\
\hline Missing & $1.3(1.0$ to 1.7$)$ & & $1.2(0.9$ to 1.6$)$ & \\
\hline
\end{tabular}




WHAT IS ALREADY KNOWN ON THIS TOPIC
Dementia is associated with an increased risk of death
No estimate exists for actual survival with dementia in
England and Wales
WHAT THIS STUDY ADDS
People with incident dementia survive on average for
4.5 years
Survival varies between 10.7 and 3.8 years between younger
old and oldest old
Sex and disability influence survival

follow-up period, $356(81 \%)$ individuals died. Survival from estimated onset of dementia was 4.6 years for women and 4.1 years for men (table 2), with a significant trend for age.

In the univariate analysis, those with higher education had slightly shorter survival than those with lower education, but this did not reach conventional significance. Social class showed no pattern. Though those who assessed their health as "poor" before the onset of dementia had shorter survival (3.8 years) than those who assessed their health as "excellent" ( 4.9 years), the difference was not significant. None of these non-significant variables was put in the multivariable Cox's proportional hazards regression model. Married individuals with dementia had the longest median survival (7.0 years for married/cohabiting, 4.4 years for widowed/separated, and 3.3 years for single), while widowed men had the shortest survival (table 3).

Those who were functionally impaired, older, and male had predicted shorter survival, but accommodation type, marital status, and score on the mini-mental state examination were no longer associated with survival (table 3).

\section{DISCUSSION}

\section{Summary of findings}

In a large population based sample, survival after the estimated onset of dementia was 4.6 years for women and 4.1 years for men. Survival was influenced by age, sex, and disability before onset. Accommodation type, marital status, and self reported health were not associated with survival once we controlled for other factors. An estimate of the expected survival after the onset of dementia is a useful measure for individuals, families, and society. Clinicians and those providing care for patients with dementia are often asked to provide a sense of how long the patient might survive. There is often a delay in recognition of dementia and formal diagnosis, which clinicians need to consider when using the best estimate in each clinical case. Knowing which factors influence the length of survival is also important.

Our findings might be limited because often we did not exactly know the timing of onset of dementia and used an estimate as the midpoint between interviews.
This is unlikely to have introduced bias as most individuals were captured by the design.

\section{Limitations}

In our cohort participants who died rapidly after onset could not be diagnosed and thus cannot be included in the survival analysis of those with incident dementia. This could lead to an overestimate of the survival time. Analysis of attrition for this study has shown that individuals who dropped out or refused follow-up during the study tended to have impaired cognitive ability and higher mortality. ${ }^{29} \mathrm{We}$ therefore potentially missed this type of incident case. Few previous studies have investigated mortality with dementia in the community based on incident cases but this is probably the measure of most value to clinicians and families ${ }^{13}$ and can be adjusted by clinicians to take into account the lag between onset and the time a clinician estimates an individual would have fulfilled dementia criteria. We did not attempt to split the sample further by subtype as the neuropathology is often mixed in the population. ${ }^{30}$ Clinical studies have examined the relation between particular syndrome profiles and survival, but we did not cover this and aimed to provide broad groups for easier application and which are available for all individuals.

\section{Findings in context of the literature}

The Canadian Study of Health and Ageing used estimated survival from incidence by basing an analysis on prevalent cases but measuring survival from an estimated earlier time of onset. Median survival times are shorter, perhaps because of this design feature and the shorter duration of follow-up (five years). ${ }^{19}$ The estimates from a French epidemiological study on brain ageing (PAQUID) are similar to ours. ${ }^{13} \mathrm{~A}$ further study from the US did not include institutions, possibly leading to longer estimated survival times than ours. ${ }^{10}$

As expected, we found significant trends of decreasing survival with increasing age for women and men, in line with others. ${ }^{31013}$ The absolute differences are large, with more than five years' difference between the youngest and oldest groups. Women with dementia have longer survival than men in our study and others. ${ }^{1013}$

We did not find strong educational effects. Univariate analysis suggests shorter survival for people with more education, as reported in some of the literature ${ }^{13}$ but not in other studies. ${ }^{31}$ These discrepancies might be caused by variation in the nature of variables adjusted in multivariable analysis. Although individuals in institutions do live for a shorter time, this is also accounted for by other factors measured in this study. ${ }^{1321}$

Lower cognitive function and dementia shorten survival, but our analysis shows that once other factors are controlled for, cognitive level within dementia is no longer significant. It is useful to know survival for specific mini-mental state examination bands as these can be applied directly for clinical use. Survival is lower by more than two years in those who cannot do the 
mini-mental state examination compared with those with higher scores, perhaps highlighting a more aggressive course. Severe comorbidity is unlikely to account for these findings as such individuals are less likely to be interviewed and are under-represented.

Disability with dementia is still associated with shorter survival, even when other factors are taken in account, as found in other studies, ${ }^{32}$ with around a three year absolute reduction in survival between the most and least disabled. This does suggest that the frailer individuals are at higher risk even after age is considered.

Other studies have estimated associations between mortality and baseline variables without taking into account changes in these variables during followup. ${ }^{1032}$ Our analysis uses values from the interview closest to onset with the intention of providing more clinically useful estimates. The major strengths of our study include its representative sampling from the population (including institutions), prospective study design, detailed measures on individuals before onset of dementia, and length of follow-up (14 years). Our analyses provide robust population based estimated survival for incident dementia by age, sex, and setting. Some of these results may seem self evident but they answer questions asked by those caring for and advising people with dementia. We hope the estimates will be valuable to patients, clinicians, carers, service providers, and policy makers.

We thank colleagues in the cognitive function and ageing study group for their cooperation in data collection and management. We are also gratefu to all the respondents, their families, and their primary care teams from across the country for their continued participation in the study. Contributors: All authors contributed to writing the paper. CB initiated the study. JX undertook the analysis and prepared the manuscript. CB and FEM supervised the work and edited the paper. JX is guarantor of the data analysis. CB is overall guarantor for the whole study.

Funding: Medical Research Council and Department of Health (grant No: G9952).

Competing interests: None declared.

Ethical approval: Multi-centre research ethics committee approval and ethical approval from the relevant local research ethics committees. Provenance and peer review: Not commissioned; externally peer reviewed.

1 Ferri CP, Prince M, Brayne C, Brodaty H, Fratiglioni L, Ganguli M, et al. Global prevalence of dementia: a Delphi consensus study. Lancet 2005;366:2112-7.

2 Comas-Herrera A, Wittenberg R, Pickard L, Knapp M, MRC-CFAS. Cognitive impairment in older people: its implications for future demand for services and costs . Canterbury: Personal Social Services Research Unit, 2003. (Discussion paper 1728.)

3 Waring SC, Doody RS, Pavlik VN, Massman PJ, Chan W. Survival among patients with dementia from a large multi-ethnic population. Alzheimer Dis Assoc Disord 2005;19:178-83.

4 Fitzpatrick AL, Kuller LH, Lopez OL, Kawas CH, Jagust W. Survival following dementia onset: Alzheimer's disease and vascular dementia. J Neurol Sci 2005;229-30:43-9.

5 Freels S, Nyenhuis DL, Gorelick PB. Predictors of survival in African American patients with $\mathrm{AD}, \mathrm{VaD}$, or stroke without dementia. Neurology 2002;59:1146-53.

6 Guehne U, Angermeyer MC, Riedel-Heller S. Is mortality increased in mildly cognitively impaired individuals? A systematic literature review. Dement Geriatr Cogn Disord 2006;21:403-10.

7 Dewey ME, Saz P. Dementia, cognitive impairment and mortality in persons aged 65 and over living in the community: a systematic review of the literature. Int J Geriatr Psychiatry 2001;16:751-61.
8 Gussekloo J, Westendorp RG, Remarque EJ, Lagaay AM, Heeren TJ, Knook DL. Impact of mild cognitive impairment on survival in very elderly people: cohort study. BMJ 1997;315:1053-4.

9 Knopman DS, Rocca WA, Cha RH, Edland SD, Kokmen E. Survival study of vascular dementia in Rochester, Minnesota. Arch Neurol 2003;60:85-90.

10 Larson EB, Shadlen MF, Wang L, McCormickWC, Bowen JD, Teri L, et al. Survival after initial diagnosis of Alzheimer disease. Ann Intern Med 2004;140:501-9.

11 Koopmans RT, Ekkerink JL, van WC. Survival to late dementia in Dutch nursing home patients. J Am Geriatr Soc 2003;51:184-7.

12 Molsa PK, Marttila RJ, Rinne UK. Long-term survival and predictors of mortality in Alzheimer's disease and multi-infarct dementia. Acta Neurol Scand 1995;91:159-64.

13 Helmer C, Joly P, Letenneur L, Commenges D, Dartigues JF. Mortality with dementia: results from a French prospective community-based cohort. Am J Epidemiol 2001;154:642-8.

14 Baldereschi M, Di CA, Maggi S, Grigoletto F, Scarlato G, Amaducci L, et al. Dementia is a major predictor of death among the Italian elderly. ILSA Working Group. Italian Longitudinal Study on Aging. Neurology 1999;52:709-13.

15 Aguero-Torres H, Fratiglioni L, Guo Z, Viitanen M, Winblad B. Prognostic factors in very old demented adults: a seven-year followup from a population-based survey in Stockholm. J Am Geriatr Soc 1998;46:444-52.

16 Ishizaki T, Yoshida H, Suzuki T, Watanabe S, Niino N, Ihara K, et al. Effects of cognitive function on functional decline among community dwelling non-disabled older Japanese. Arch Gerontol Geriatr 2006;42:47-58.

17 Juva K, Verkkoniemi A, Viramo P, Polvikoski T, Kainulainen K, Kontula K, et al. APOE epsilon4 does not predict mortality, cognitive decline, or dementia in the oldest old. Neurology 2000;54:412-5.

18 Boersma F, Van Den BW, Deeg DJ, Eefsting JA, Van TW. Survival in a population-based cohort of dementia patients: predictors and causes of mortality. Int J Geriatr Psychiatry 1999;14:748-53.

19 Guero-Torres H, Fratiglioni L, Guo Z, Viitanen M, Winblad B. Mortality from dementia in advanced age: a 5-year follow-up study of incident dementia cases. J Clin Epidemiol 1999;52:737-43.

20 Landi F, Gambassi G, Lapane KL, Sgadari A, Mor V, Bernabei R. Impact of the type and severity of dementia on hospitalization and survival of the elderly. The SAGE Study Group. Dement Geriatr Cogn Disord 1999;10:121-9.

21 Van Dijk PT, Dippel DW, Habbema JD. Survival of patients with dementia. J Am Geriatr Soc 1991;39:603-10.

22 Noale M, Maggi S, Minicuci N, Marzari C, Destro C, Farchi G, et al. Dementia and disability: impact on mortality. The Italian longitudinal study on aging. Dement Geriatr Cogn Disord 2003;16:7-14.

23 Ostbye T, Steenhuis R, Wolfson C, Walton R, Hill G. Predictors of fiveyear mortality in older Canadians: the Canadian study of health and aging. J Am Geriatr Soc 1999;47:1249-54.

24 Matthews F, Brayne C. The incidence of dementia in England and Wales: findings from the five identical sites of the MRC CFA Study. PLoS Med 2005;2:e193.

25 Brayne C, Gao L, Dewey M, Matthews FE. Dementia before death in ageing societies-the promise of prevention and the reality. PLoS Med 2006;3:e397.

26 Neale R, Brayne C, Johnson AL. Cognition and survival: an exploration in a large multicentre study of the population aged 65 years and over. Int J Epidemiol 2001;30:1383-8.

27 Copeland JR, Dewey ME, Griffiths-Jones HM. A computerized psychiatric diagnostic system and case nomenclature for elderly subjects: GMS and AGECAT. Psychol Med 1986;16:89-99.

28 Folstein MF, Folstein SE, McHugh PR. "Mini-mental state". A practical method for grading the cognitive state of patients for the clinician. J Psychiatr Res 1975;12:189-98.

29 Matthews FE, Chatfield M, Brayne C. An investigation of whether factors associated with short-term attrition change or persist over ten years: data from the Medical Research Council cognitive function and ageing study (MRC CFAS). BMC Public Health 2006;6:185.

30 Fernando MS, Ince PG. Vascular pathologies and cognition in a population-based cohort of elderly people. J Neurol Sci 2004;226:13-7.

31 Geerlings MI, Deeg DJ, Penninx BW, Schmand B, Jonker C, Bouter LM, et al. Cognitive reserve and mortality in dementia: the role of cognition, functional ability and depression. Psychol Med 1999;29:1219-26.

32 Ostbye T, Hill G, Steenhuis R. Mortality in elderly Canadians with and without dementia: a 5-year follow-up. Neurology 1999;53:521-6.

Accepted: 11 November 2007 